\title{
Margen de intermediación y concentración bancaria en Colombia: un análisis para el periodo 2000-2017
}

\section{Intermediation margin and banking concentration in Colombia: an analysis for the period 2000-2017}

DOI: https://doi.org/10.17981/econcuc.40.2.2019.01

Artículo de Investigación. Fecha de recepción: 20/11/2018 Fecha de aceptación: 19/06/2019

José Mauricio Gil León

Universidad Pedagógica y Tecnológica de Colombia. (Tunja, Colombia)

josemauricio.gil@uptc.edu.co

Dilsa Eliyer Castellanos Castellanos

Universidad Pedagógica y Tecnológica de Colombia. (Tunja, Colombia)

dilsa.castellanos@uptc.edu.co.

Diego Leonardo González Rodriguez

Universidad Pedagógica y Tecnológica de Colombia. (Tunja, Colombia)

diegoleonardo.gonzalez@uptc.edu.co

Para citar este artículo:

Gil, J., Castellanos, D. y Gonzáles, D. (2019). Margen de intermediación y concentración bancaria en Colombia: un análisis para el periodo 2000-2017. Económicas CUC, 40(2). 9-30. DOI: https://doi.org/10.17981/econcuc.40.2.2019.01

\section{Resumen}

Durante los años 90 se promovieron reformas dirigidas a reencaminar el futuro de la banca en Colombia lo cual permitió una estructura de mercado mejor consolidada, no sólo para las entidades financiera sino también para las Corporaciones de Ahorro y Vivienda. En este entendido, la presente investigación pretende explicar la relación entre el margen de intermediación bancaria y la concentración del sector en Colombia, desde la hipótesis que una mayor concentración lleva a los bancos a tener una diferencia más importante entre la tasa de colocación y la tasa de captación. La concentración se mide con el Índice de Herfindahl-Hirschman de los activos bancarios del país, deduciendo que entre 2000 y 2010 creció en forma importante por las fusiones y adquisiciones de los bancos, y a partir de ese año se tendió a estabilizar. Para evidenciar de manera clara la relación se estima un modelo ARDL, y se obtienen efectos positivos de largo plazo de la concentración bancaria, la inflación, la variación del PIB real y la tasa de encaje sobre el diferencial de tasas de interés.

Palabras clave: Tasas de captación; tasas de colocación; inflación; actividad económica

\begin{abstract}
Through the 90's, reforms aimed at redirecting the future of banking in Colombia were promoted, resulting in a better consolidated market structure, not only for financial entities but also for Savings and Housing Corporations. In this understanding, this research aims to explain the relationship between the bank intermediation margin and the concentration of the sector in Colombia, from the hypothesis that a higher concentration leads banks to have a more important difference between the placement rate and the rate uptake. Concentration is measured with the Herfindahl-Hirschman Index of the country's banking assets, deducing that between 2000 and 2010 it grew significantly due to bank mergers and acquisitions, and since that year it tended to stabilize. To clearly show the relationship, an ARDL model is estimated, and it has positive long-term positive effects of bank concentration, inflation, the variation in real GDP and the reserve requirement on the interest rate differential.
\end{abstract}

Keywords: Active interest rates; passive interest rates; inflation; economic activity. 


\section{INTRODUCCIÓN}

"En los países del mundo y en especial los de Latinoamérica, el gobierno central le ha trasladado la responsabilidad del propio desarrollo" (Guerrero y Noriega, 2015, p. 134). Para las organizaciones, en Colombia, a partir de la década de los años 90 se impulsaron reformas encaminadas a transformar la banca especializada de la época hacia el nuevo esquema de multibanca, generando que los costos de funcionamiento para el sector en general sean menores y permitiendo que todos los bancos comerciales pudieran realizar el mismo tipo de operaciones, y así, tanto los bancos como las Corporaciones de Ahorro y Vivienda (CAV) se afiancen en la nueva estructura de mercado.

En el transcurso de la década de los noventa se originó un "boom" crediticio, debido principalmente a las bajas tasas de interés que establecieron las CAV. Esto permitió otorgar un alto número de préstamos destinados a la compra de vivienda, sin tener en cuenta el respaldo de los deudores hacia dichos créditos. Además, la reducción en el precio del inmueble y al repentino aumento de la tasa de interés se presentó un incremento en el riesgo de la cartera, porque los prestatarios empezaron a encontrar dificultades para responder con sus obligaciones crediticias. Esto junto a la baja regulación por parte de los entes encargados se permitió que se desatara una crisis en el sector a finales del decenio.

Posteriormente, mediante la Ley 510 (1999) todas las CAV debían convertirse en bancos comerciales a más tardar para el año 2002 , estableciendo un nuevo marco regulatorio para la concesión de créditos en la actividad hipotecaria; además, la crisis desencadenó procesos de fusiones y adquisiciones, reduciendo así el número de entidades dedicadas a dicha actividad, las cuales se convirtieron en bancos hipotecarios y desaparecieron después de 2015.

En cierto modo, la crisis del sector generó un aumento en los niveles de concentración, llevando a que en la actualidad cuatro grupos financieros controlen gran parte del mercado, considerando la participación en los activos totales del sector, la cuantía de clientes y la cobertura en servicios, los cuales se han venido fortaleciendo gracias a la inversión extranjera y a la expansión en el exterior de la banca local.

La recuperación y la consolidación del sector ha sido favorable entre los años $2000 \mathrm{y}$ 2017, unido de una mayor regulación bancaria. El buen desempeño se refleja en los indicadores de: rentabilidad, riesgo, liquidez y solvencia. Esta recuperación hace que se enfoquen esfuerzos para aumentar los niveles de profundización financiera en el país, porque en contraste con otros países de la región el sector colombiano presenta niveles bajos.

La rentabilidad de las entidades bancarias colombianas, calculada como la razón entre la utilidad y el activo promedio, muestra que se han venido recuperando a partir del año 2000 , posterior al suceso de crisis de finales de los años noventa, causada principalmente por los bancos de origen nacional. -Es así como-, para los dos primeros años de la década la rentabilidad de los bancos nacionales supera en 1,6 pp la rentabilidad de los bancos extranjeros, representando $1,41 \%$ y $-0,21 \%$, respectivamente.

La intermediación financiera para analizar la rentabilidad ex-ante, se estudia mediante las tasas de captación y colocación con el fin de identificar el ingreso obtenido por cada peso de cartera colocado y el costo de cada peso captado, para el periodo 20012002 la tasa activa es del $15,7 \%$ y la tasa pasiva de 6,9\% a septiembre del año 2002 . El margen de intermediación para este periodo 
osciló entre $7,6 \%$ y $8,2 \%$, permitiendo que los bancos obtengan mayores ingresos en su actividad. Despues de 2014 el margen de intermediación se reduce, al llegar al 6,5\% a finales del primer semestre del 2014, dado que, las tasas de captación disminuyeron en 0,1pp al pasar al 4,3\% y las de colocación se incrementan en 0,6pp al ubicarse en 10,9\%.

Por tal razón, este artículo pretender analizar el papel de la concentración bancaria en el margen de intermediación financiera, considerando como hipótesis que el incremento en la concentración bancaria ha elevado el poder de mercado, y así los bancos pueden elevar la tasa de colocación sin necesidad de modificar demasiado la tasa de captación. Se encuentra distribuido en seis secciones, considerando la introducción como la primera. La segunda realiza una revisión de literatura acerca de los estudios relacionados en Colombia. En la tercera se realiza una caracterización del sector bancario según el proceso de concentración. Para la cuarta se estima con el IHH la concentración. Y en la quinta se estima la incidencia de la concentración bancaria en el margen de intermediación. Finalmente, se señalan unas conclusiones del estudio.

\section{Antecedentes}

En la década de los años 90 se evidenciaron bajos niveles de competencia en el sector bancario colombiano, porque las entidades bancarias presentaron una gran divergencia en los costos operativos que permitian que en la industria bancaria pudiera existir establecimientos con malas administraciones, lo que llevó a un bajo nivel de competencia en el sector, generando así ineficiencia operativa (Suescún \& Misas, 1996). Por tanto, corregir estas fallas permite al beneficio social y privado mejorar, mediante la asignación de recursos, precios y calidad de los servicios.
Los bancos colombianos se clasifican en dos grupos, eficientes y menos eficientes. Los bancos eficientes son aquellos que tienen menores costos operativos, mientras los bancos no eficientes tienen mayores costos operativos, representando el 33\% de los costos totales, a su vez los costos laborales representan el $61 \%$ de los costos operativos de los bancos eficientes y el $67 \%$ de los mismos para los bancos menos eficientes (Suescún \& Misas, 1996).

Sin embargo, para el periodo 1989-1995 los bancos eficientes produjeron el $28 \%$ del crédito y los bancos ineficientes produjeron el $72 \%$ restante, el sistema bancario en general podría reducir los costos operativos en un $3,34 \%$, si todos los bancos operan en el nivel óptimo de planta y utilizaran la tecnología adecuada (Suescun \& Misas, 1996).

Por otra parte, Steiner, Barajas y Salazar (1997) distinguen dos tipos de bancos respecto al tipo de propiedad, clasificándolos en bancos oficiales y los bancos privados, evidenciando que los bancos colombianos funcionan bajo un esquema no competitivo. El análisis fue empírico y se realizó a través de la estimación de un modelo de datos panel, lo cual reveló que en promedio el margen de intermediación era del $26 \%$ de la tasa de interés de colocación respecto de la tasa de interés de captación, indicando a su vez que los bancos tenían un elevado poder de mercado, e implicando así bajos niveles de competencia en el sector (Steiner, Barajas \& Salazar, 1997).

En las últimas dos décadas el sistema bancario colombiano ha evolucionado de un esquema de banca especializada a un esquema de multibanca, debido a la liberalización económica general y a la necesidad de adaptar el sistema bancario a los nuevos retos que implicaba la internacionalización hacía la economía global. Las reformas implementadas después de 1999 llevaron a que 
se disminuyera el número de entidades bancarias por medio de fusiones y adquisiciones, reduciendo el nivel de competencia y

El sistema bancario colombiano transitó de una estructura muy regulada y poco competitiva en los años 80's a un esquema más libre y competitivo en la década de los años 90’s, y se caracterizó por el desvanecimiento continuo de las CAV ordenado por la Ley 546 de 1999 para consolidar una estructura bancaria más integrada (Clavijo, 2000). Asimismo, el aumento de la inversión extranjera directa en la banca en la década del 90 alcanzó el 18\% de los activos totales, esto sirvió de estimuló para fomentar una competencia progresiva, permitiendo que los consumidores se beneficiaran de más servicios a menores costos (Clavijo, 2000).

La concentración de la propiedad bancaria en Colombia fue consecuencia de los procesos de fusión y adquisición efectuados a finales de los años noventa, los cuales se agudizaron por la crisis que se desató por la burbuja inmobiliaria. Evidencia es la distribución del activo bancario total, ya que, tan solo cuatro grupos financieros poseían el $47 \%$ del activo del sistema, el restante de los activos totales corresponden al $22 \%$ en manos de entidades estatales y el $31 \%$ a entidades privadas (Clavijo, 2000).

Los resultados financieros de los bancos son consecuencia de las transacciones de captación, colocación y de los costos de funcionamiento. De igual manera, como la economía en general sufrió cambios drásticos debido a la implementación de las leyes aperturistas que se llevaron a cabo en la década de los 90, lo cual impulsó la competencia en todos los sectores de la economía, dada la menor regulación por parte del Estado y el impulso a la desnacionalización de la banca, expresado en el aumento de la inversión extranjera en el sector (Jiménez \& Jaramillo, 2001).
En el estudio de Jiménez y Jaramillo (2001) se afirma que la aplicación del consenso de Washington en la economía colombiana por medio de la apertura económica convierte al sector bancario en un mercado potencial para la banca de países desarrollados, que encontraron un bajo desarrollo bancario, altos márgenes de intermediación y un escenario en el cual tan solo estaba dando inicios la reforma de desregulación y apertura del sector.

Para el año 2003, las reformas establecidas en los años 90, transformaron al sistema financiero en general. En cuanto a la estructura interna, estas reformas se llevaron a cabo con el fin de ahorrar costos para poder permanecer en el negocio, y a finales de la crisis las autoridades otorgaron una serie de incentivos para salvar algunas entidades y frenar esta dificultad (Janna, 2003).

Además, la ineficiencia del sector bancario más que depender de si los activos son de propiedad pública o estatal, depende del grado de competencia que exista en el sector, es así como, la reducción de la ineficiencia para el periodo 1992-1997 dependió de cambios en las condiciones del sector en general en un $72 \%$, el $32 \%$ hacen parte de las modificaciones regulatorias y el $40 \%$ de la ampliación de la competencia y el restante corresponde a las políticas internas de control de los bancos (calidad del producto, tipo de propiedad) (Janna, 2003).

El informe de la Asociación Nacional de Instituciones Financieras (ANIF) para el año 2005, denominado "Fusiones y Adquisiciones en el Sector Financiero Colombiano: Análisis y Propuestas sobre la Consolidación Bancaria (1990-2006)" evidencia como el sistema bancario colombiano tuvo un ciclo en el que vivió diferentes etapas coyunturales, recuperación, expansión, sobredimensionamiento, crisis y recuperación (ANIF, 2006). 
Las fusiones y adquisiciones en el sector bancario son el resultado de un proceso gradual, que ha estado presente en cada una de las etapas de este ciclo y obedecen a la necesidad de actualización del sistema para que este sea más eficiente y competitivo; en el periodo de crecimiento, el número de entidades financieras eran 201, durante el periodo de crisis se redujeron a 126 y se estimó que para el 2006 tan solo habrían 77 entidades financieras, no obstante, el grado de concentración bancaria no necesariamente está directamente relacionado con la estructura organizativa (multibanca, banca especializada) (ANIF, 2005).

Bernal (2007) expone que, en el año 2004, Colombia presentó el menor índice de concentración bancaria después de Panamá. De acuerdo al resultado del índice Herfindahl Hirschman (IHH), el nivel de concentración está relacionado con reducciones en el nivel de competencia que se pueden traducir en mejoras o disminuciones en los niveles de bienestar de la sociedad; asimismo, el poder de mercado de cada entidad financiera depende en gran medida de la cantidad de ganancias que esta obtenga y define la participación en el mercado (Bernal, 2007).

Para el periodo de estudio, las fusiones efectuadas buscaron crear economías de alcance que permitieran diversificar los productos y servicios financieros, además, la competencia internacional presionó a las entidades bancarias a incursionar en nuevos tipos de cartera y de negocios. Es así, como, a finales de 2005 se produjeron en Colombia los procesos de fusión más importantes cuando los Bancos Especializados en Cartera Hipotecaria (BECH) fueron absorbidos por bancos comerciales (Bernal, 2007).

De acuerdo con Estrada (2005), cuando surgen fusiones en cualquier tipo de industria, se generan preocupaciones acerca del impacto que puede ocasionar la concentración y el efecto de la competencia en el mercado, a nivel colombiano el índice de concentración del sistema no es tan elevado. En este contexto, la llegada de bancos extranjeros después de la eliminación de las barreras de entrada no permitió el aumento de la concentración bancaria, lo anterior puede conducir a la consolidación de un sistema más competitivo y eficiente.

El sector bancario colombiano presentó un ciclo de elevado crecimiento entre los años 2006 y 2009 , debido al aumento en la cartera de los bancos y a los incrementos en los precios. Por ende, las autoridades competentes implementaron medidas encaminadas al control de capitales, encajes y una política monetaria más rigurosa en cuanto a la tasa de interés, las medidas anteriores permitieron que la crisis internacional no tuviera efectos sobre el sector bancario y la economía colombiana en general (Morales, 2011).

Asimismo, en el año 2008 se adoptó el Sistema de Administración del Riesgo Crediticio (SARC) que incluía aportes de Basilea II y con ello se les dio entrada a nuevas entidades especializadas en microcrédito, generando efectos positivos en la profundización financiera y en la bancarización, mas no cambios en la concentración (Morales, 2011).

A su vez, el informe de la Organización para la Cooperación y el Desarrollo Económicos (OCDE) para Colombia asegura que la profundización financiera es insuficiente y el sector privado aún carece de la financiación necesaria para emprender sus proyectos, ya que, representa tan solo el $41 \%$ del PIB y el promedio de los países miembros de la OCDE está por encima del 150\% del PIB. En cuanto a la competencia, el informe menciona que se puede aumentar evitando la concentración excesiva por medio de regulaciones que busquen reducir el costo de la financiación y mejorar el acceso al sistema bancario (OCDE, 2017). 
La relación entre concentración y competencia no es completa, una elevada concentración no implica estrictamente un bajo nivel de competencia, no obstante, una banca más concentrada puede generar estímulos en los bancos para aumentar los precios competitivo (Montoya, Martínez, Lacouture \& Castillo, 2015). Por otra parte, el sector bancario colombiano para el período 20022014 ha tenido un elevado nivel de crecimiento en sus activos, atrayendo el ingreso de nuevas entidades al sector, pasando de 18 establecimientos en el 2008 a 24 en el año 2014, además, la incursión de entidades extranjeras a la industria bancaria ha llevado a que se dinamice el sector y sea más competitivo.

En el documento "Estudios económicos de la OCDE Colombia" se menciona que a pesar de la fuerte regulación en el sector bancario colombiano por parte de la Unidad de Regulación Financiera (URF) y la Superintendencia Financiera de Colombia (SFC), la reciente expansión de las entidades de crédito a países centroamericanos trae consigo un posible efecto de contagio por la fragilidad de estas economías y para mitigar este riesgo se propone reforzar medidas regulatorias sobre los conglomerados financieros y los Holding (OCDE, 2017).

La apuesta del Gobierno Nacional es promover el acceso, uso y educación en cuanto a los servicios financieros, para esto se implementa la Ley 1735 (2014), como una estrategia nacional para la inclusión financiera dirigida a aumentar el número de participantes en el sector financiero (OCDE, 2017).

Por último, en el informe "Actualidad del Sistema Financiero Colombiano-2017", se evidencia que los activos de los Establecimientos de Crédito (EC) han tenido una tendencia positiva respecto al año anterior, creciendo en 34,5 billones de pesos, para un total de 608,5 billones de pesos a diciembre de 2017, así mismo, en el informe se detalla que los EC reportaron 8,3 billones de utilidades de las cuales 7,7 billones corresponden a los bancos, manifestándose así la importancia del sector. En la actualidad se considera que el sector está muy bien consolidado gracias a las dinámicas de concentración y competencia como efecto de la regulación estatal de tipo micro y macroprudencial.

\section{Características de sector bancario colombiano}

"El orden global entró en proceso de transformación hacia un nuevo orden mundial que rigió las reglas de juego" (González, Galeano y Trejos, 2015, p. 80) para la recuperación del sector bancario colombiano a inicios de la década del 2000, se llevó a cabo por medio de reformas, tales como la Ley 510, la cual establece que las entidades que no cumplan con el requerimiento mínimo de capital se deben liquidar, fusionar o convertir en otro tipo de entidad regulada por la Superbancaria (Ley 510, 1999). La Ley 546 (1999) promulga, que las corporaciones de ahorro y vivienda (CAV's) deberían transformándose en bancos comerciales (Ley 546, 1999).

Por otra parte, se generaron fusiones $\mathrm{y}$ adquisiciones en el sector con el fin de fortalecerlo, haciendo a las entidades más eficientes para crecer y poder permanecer en los mercados globalizados por medio del uso de las economías de escala. Las fusiones y adquisiciones se llevaron a cabo con el fin de conseguir crecimiento en el sector, permitiéndole a las entidades incursionar en el mercado global (Cárdona \& Restrepo, 2012; Zuñiga, 2017).

En la banca colombiana se ha dado un proceso de evolución en el número de bancos de acuerdo a los sucesos de fusión, adquisición, bancos quebrados y nuevos bancos. Para enero del año 2000, la CAV AV Villas surge 
como resultado de la fusión de Ahorramás a las Villas, en el mes de febrero la CAV BCH, realiza cesión parcial de sus activos a la nueva entidad bancaria y en el mes de marzo el banco Anglo Colombiano cambia su razón social a Lloys Tsb Bank (ANIF, 2006).

Otros procesos de cesiones de activos, pasivos y contratos que se llevaron a cabo en el año 2000 fueron los realizados por Leasing Superior hacia el Banco Superior, de Banestado al Banco Agrario. Además, la CAV Colmena se convierte en el banco Colmena, BBVA absorbe la compañía financiera Corfigan y Davivienda adquiere a la CFC Delta Bolívar (Estrada, 2005; Zuñiga, 2017).

Asimismo, a inicios del año 2000 la Superbancaria informa que los bancos Pacifico, Andino y Selfin serían liquidados debido a que presentaron perdidas en los balances generales. En el año 2001 el banco Sudameris Colombia absorbe Leasing Sudameris, se genera la conversión de Aliadas CFC a banco Aliadas y adquiere mediante cesión parcial a la CFC financiera Fes y a Interbanco, de igual forma, se da la conversión de la CAV Conavi a banco Conavi y en octubre del mismo año, la CAV Granahorrar se convierte a banco Granahorrar y Davivienda por su parte realiza cesión parcial de la corporación financiera del norte (Cofinorte). Posteriormente, para el año 2002, surge la conversión a banco de la CAV AV Villas (Estrada, 2005).

En el periodo 2005-2006 acontecieron las fusiones más importantes del sector, ya que, entidades como Bancolombia, Davivienda, BBVA, entre otras, se fortalecen por medio de la adquisición de bancos con menor participación, en el caso de Bancolombia, adquiere Corfinsura y el Banco Conavi, el Banco Caja Social se fusiona con el Banco Colmena S.A., el Banco Sudameris Colombia con el Banco Tequendama, el Banco de Occidente con el Banco Aliadas y el Banco Unión Colombiano, el Banco de Bogotá adquiere el Banco de cré- dito y desarrollo social Megabanco, el Banco BBVA absorbe al Banco Granahorrar y el banco Davivienda adquiere a Bansuperior.

El año 2007 trae consigo operaciones que continúan modificando la estructura del sector bancario, Davivienda adquiere a Granbanco, mediante un proceso de fusión y con ello a las filiales Fiducafé S.A, Bancafé Panamá y Bancafé Internacional Miami (Upegui, 2014), además, Colpatria mediante un proceso de fortalecimiento por medio de un "joint venture" se asocia con General Electric adquiriendo el 22,85\% de la compañía (Revista Dinero , 2008). En el transcurso del siguiente año, el banco BBVA establece la formación de una fundación para combatir la exclusión financiera, fomentando el microcrédito en poblaciones de bajos recursos, dando origen al banco de las microfinanzas Bancamía, por otra parte, el banco Procredit fue creado en el mismo año, con el fin de atender y contribuir al desarrollo, financiado por Procredit Holding AG y el BID (Mora, Serna \& Serna, 2011).

En el mes de enero del año 2009 se aprobó la conversión de la compañía financiera Coomeva a Bancoomeva y en el mes de agosto de 2010 ingresa a competir en el mercado. En el año 2010, el grupo Aval adquiere en su totalidad al banco regional centroamericano Bac Credomatic, permitiendo la internacionalización de la banca colombiana, al mismo tiempo, la SFC autoriza la conversión a banco de la compañía de financiamiento Finandina, de igual forma, la compañía de financiamiento inversora Pichincha ingresa al país en el año 2004 y para el 2010 se transforma a banco (Mora, Serna \& Serna, 2011).

Scotiabank (grupo financiero canadiense) ingresa al país en el año 2011 y adquiere el 51\% de las acciones del Banco Colpatria, a su vez el banco chileno Falabella inicia operaciones en el mercado nacional (Mora, Serna, \& Serna, 2011), adicionalmente, la 
fundación WWB, cambia su razón social a Banco $\mathrm{W}$, después de la autorización de la Superintendencia Financiera (Ramirez \& Romero, 2014).

En el periodo 2011-2012 se registra el ingreso de un nuevo banco al país, siendo el caso del grupo CorpBanca Chile, quien compra las operaciones del banco Santander en el año 2012 y realiza el acuerdo de compra para la adquisición de las operaciones de HSBC en Colombia, Perú, Uruguay y Paraguay. Por otra parte, el banco Davivienda adquiere las operaciones bancarias y de seguros de HSBC en Honduras, Costa Rica y El Salvador (Upegui, 2014).

Para el año 2013, el Banco Santander tras ser adquirido por CorpBanca, regresa al país con un capital destinado para atender un segmento empresarial bajo el nombre Banco Santander de negocios, de igual manera, CorpBanca adquiere al grupo Helm Bank, expandiendo sus servicios y operaciones en el país (Upegui, 2014).

A su vez, se dan otros procesos de adquisición por parte de Bancolombia, obteniendo los derechos de las operaciones del grupo mercantil Guatemala y de HBSC Panamá por un valor de US\$ 216 millones y US\$ 2100 millones, respectivamente. Del mismo modo el Grupo AVAL, adquiere al grupo reformador de Panamá y al banco BBVA de Panamá, transacciones realizadas por 411 y 490 millones de dólares respectivamente (Upegui, 2014).

En el transcurso del año 2014, se destaca el ingreso de nuevas entidades extranjeras al sector bancario, el banco chileno Mundo Mujer y el banco panameño Multibank, favoreciendo sectores del mercado como el microcrédito para las Pymes, lo cual en palabras de Pérez, Hernández, Acosta y Chumaceiro (2009) resulta ser un "factor determinante para el crecimiento económico de un país, así como para la generación de empleo sustentable y de calidad" (p. 275). Además según Bonilla, Cardeño y Cardeño (2015) "llenan vacíos en la producción de cualquier país, ya que hay un conjunto de productos que deben elaborarse a pequeña escala" (p. 139). Para la banca personal, se resalta la entrada del banco brasileño Itaú, por medio de la adquisición del $66 \%$ de los activos de CorpBanca (Ramirez \& Romero, 2014). Finalmente, para el 2014 se da un proceso de conversión en la corporación de financiamiento comercial Finamerica a Bancompartir (Ramirez \& Romero, 2014).

El Banco español Sabadell ingresa al país en el año 2015 tras la adquisición del 5\% del Banco GNB Sudameris, transacción realizada por 50 millones de dólares, al mismo tiempo se da la incursión del grupo financiero francés Natixis en el país, entidad enfocada en ofrecer servicios de banca y seguros, dada la autorización previa de la Superfinanciera (Ramírez, Gamboa \& Mesa, 2015).

En la actualidad, el sistema financiero colombiano y en particular el bancario, atraviesan un momento en el cual se introducen herramientas tecnológicas que buscan acercar a los colombianos no bancarizados a los distintos servicios que se ofrecen, los instrumentos tecnológicos que más fuerza toman son las Fintech y los Neobancos. Las Fintech son empresas financiera con alma digital que usan las últimas tecnologías para ofrecer productos y servicios innovadores; los Neobancos son una nueva generación de entidades financieras digitales, en el país se implementan estas tecnologías mediante las plataformas digitales de Bancolombia (Nequi) y Davivienda (Daviplata) (Dinero, 2018).

Los procesos de fusiones y adquisiciones se dan principalmente en el periodo 20002007, seguido de un proceso de conversión de entidades comerciales financieras a ban- 
cos, desarrollado con mayor empeño entre los años 2008-2012 aproximadamente, para los años posteriores y hasta la actualidad, se ha llevado a cabo la entrada de capitales extranjeros al sector y algunas entidades nuevas se dedican al microcrédito, en general el número de bancos ha permanecido estable (2012-2017) y actualmente se implementa el desarrollo de tecnologías para el crecimiento del sector.

Los procesos de consolidación que se llevaron a cabo hasta la primera parte de la década del 2000 permitieron el afianzamiento de cuatro principales grupos: el Grupo Aval con una participación del $28,7 \%$ en el sector, Bancolombia con un 20,8\%, Davivienda con un $12,1 \%$ y BBVA con $10,9 \%$, el restante corresponde a la participación del Banco Agrario, Sudameris, Banco Caja Social Colmena BCSC, y otras entidades extranjeras y mixtas como Global Emerging Markets, Banco Colpatria, Santander y Citibank (Dinero, 2008).
Concentración en el sector bancario colombiano

La estimación del grado de concentración del sector se realiza a través del Índice Herfindahl-Hirschman (IHH), atribuido al economista estadounidense Orris Herfindahl, quien lo propuso en su disertación doctoral "Concentation in the Steel industry" para la industria siderúrgica y al economista alemán Alberth Hirschman quien con anterioridad en 1945 había planteado un índice parecido para la concentración de mercado.

El IHH es uno de los indicadores que permiten identificar la concentración de un mercado en general, asigna una ponderación diferente a cada entidad de acuerdo con la participación que tenga en el sector, se calcula mediante (1).

$$
I H H=\sum_{i=1}^{n}\left(\frac{x i}{x} * 100\right)^{2}
$$

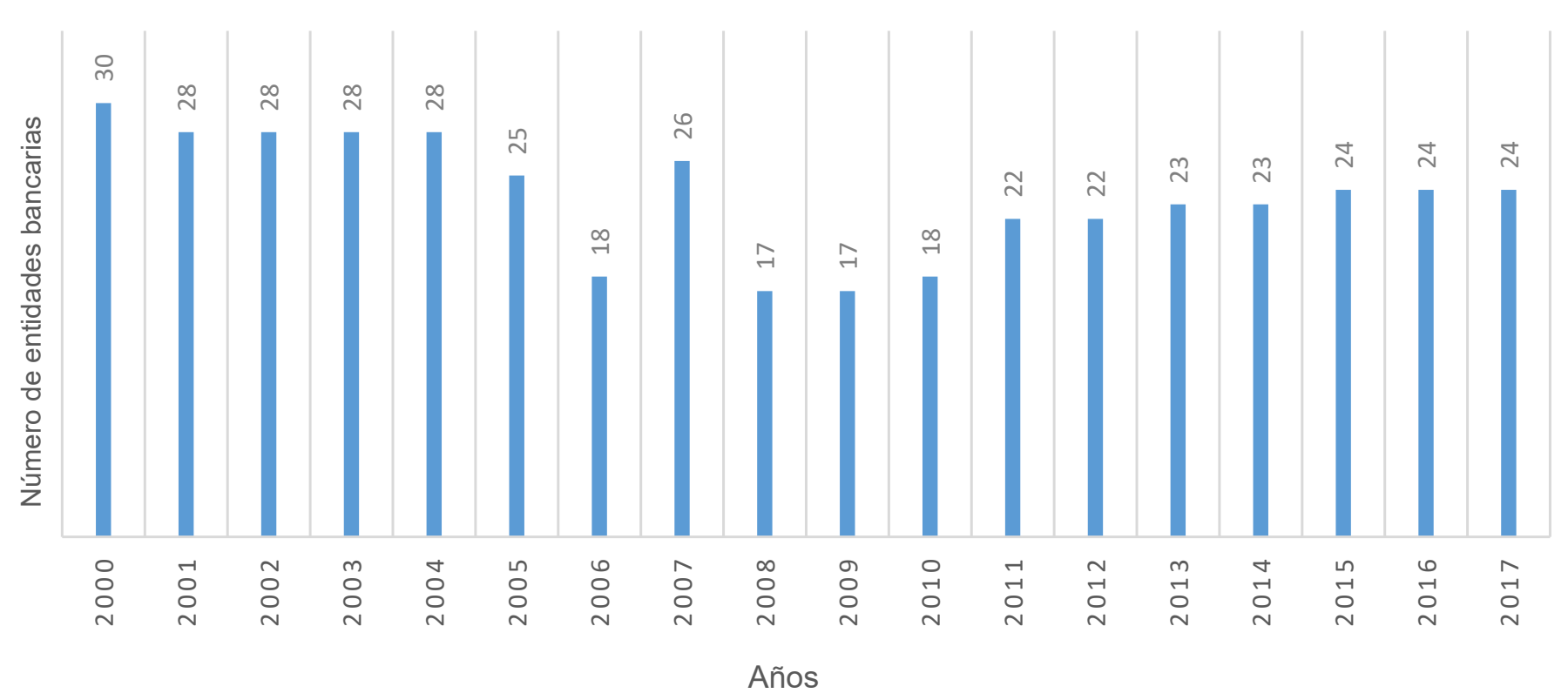

Figura 1. Evolución del número de bancos en Colombia.

Fuente: Cálculos propios de datos tomados de Superintendencia Financiera de Colombia. 
Donde, representa los activos totales de cada banco y los activos totales del sector. El IHH fluctúa entre 0 y 10000, valores comprendidos entre 0 y 1000 indican niveles bajos de concentración, entre 1000 y 1800 indican una concentración moderada y mayor a 1800 se considera que hay una elevada concentración (Morales, 2011).

El cálculo de la concentración bancaria colombiana, por medio del IHH, se realiza utilizando datos trimestrales de la participación de los bancos en el total de activos del sistema, evidenciando una tendencia positiva que se ha presentado en los últimos 17 años, atribuido a los diversos procesos de fusiones y adquisiciones de los bancos, esto, a pesar de la existencia de niveles bajos y moderados de concentración en el sector.

El IHH para el último trimestre del año 2000 fue de 648,61, evidenciando que para ese periodo existía un nivel bajo de concentración del sector, para el mismo trimestre del siguiente año el índice se reduce levemente en 34,66 puntos, y para el año 2002 se reduce a 589,85 debido a las distintas conversiones de las CAV's y compañías financieras a Bancos, fusiones y adquisiciones de entidades financieras por parte de bancos nacionales y extranjeros.

En el periodo 2003-2004 aumenta la concentración del sector debido a la adquisición de entidades por parte de los bancos que ya estaban medianamente consolidados, es así como el sector posee un IHH de 621,62 y 663,13 puntos respectivamente. La concentración del sector continúa con una tendencia positiva, para el año 2005 del total de activos del sector 8 entidades poseían el $70,3 \%$, el restante estaba distribuido en 13 entidades, para el año siguiente se evidenció un fenómeno similar, el 75\% lo poseen 8 entidades y el restante de los activos está distribuido en 9 entidades, es decir, más de la mitad de entidades tan solo posee el $25 \%$ de los activos del sector.

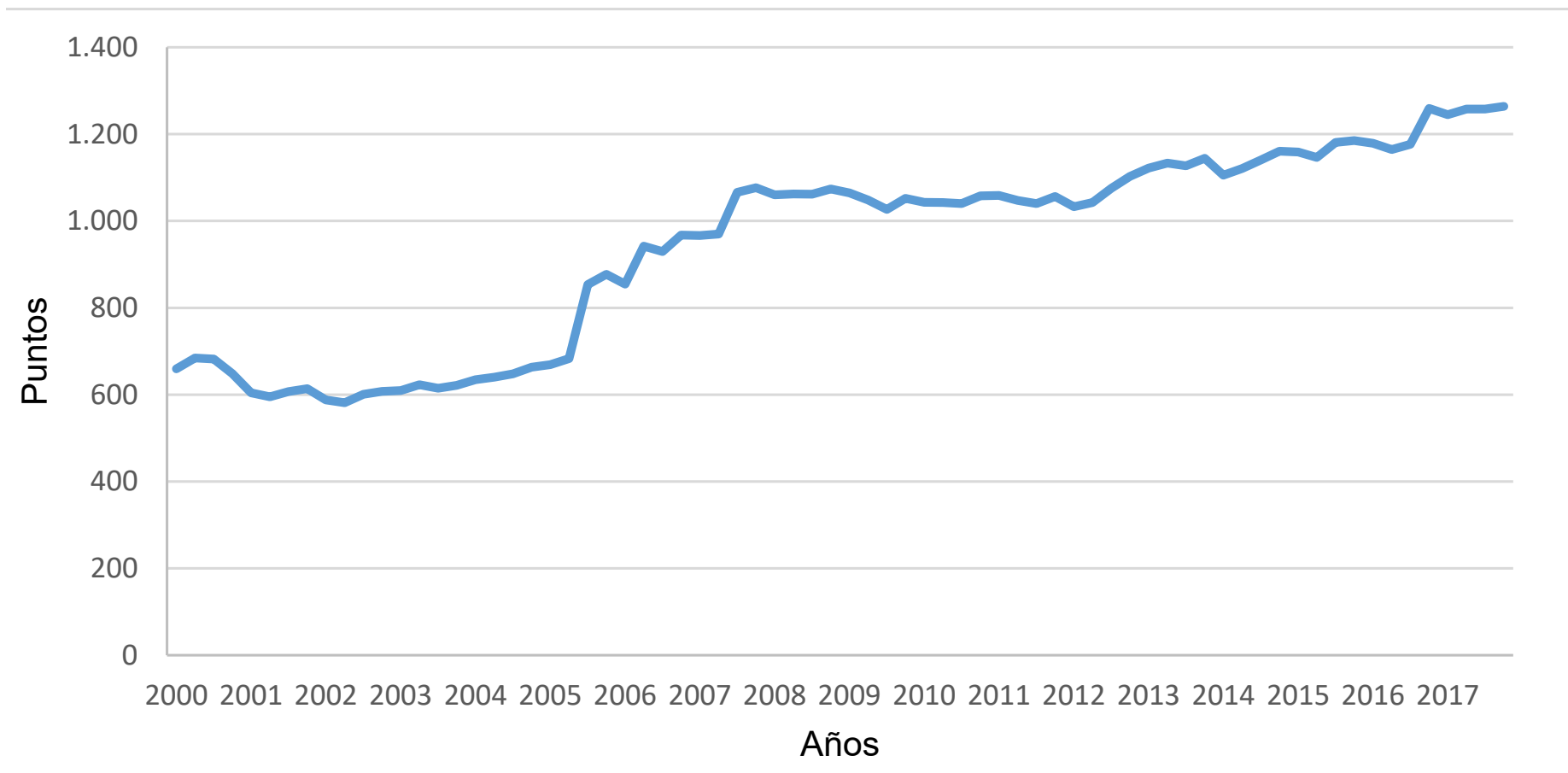

Figura 2. Índice Herfindahl-Hirschman Sector bancario colombiano 2000-2017. .Fuente: Cálculos propios de datos tomados de Superintendencia Financiera de Colombia. 
Los niveles más elevados de concentración en la década se evidenciaron en los años 2007 y 2008, donde el IHH obtiene el valor de 1076,42 y 1073,45 puntos en cada año, lo que implica que para el primer año el $64 \%$ del total de activos está concentrado en 5 entidades y el restante de los activos lo poseen 16 entidades, mientras que, para el año 2008, la mitad de las entidades tenían el $75 \%$ del total de activos del sector, la otra mitad tan solo posían el $25 \%$.

Para el periodo 2009-2011, el valor del IHH estuvo comprendido entre 1051,94 y 1055,04 puntos, presentando una leve reducción de 2,70 puntos para el año 2011. De otra parte, se constata que la concentración de los activos bancarios sigue creciendo con variaciones notorias, en el periodo 2012-2015 estuvo comprendida entre 1.102 y 1.185 puntos, presentando un crecimiento de $82,56 \mathrm{p}$ en el periodo. Finalmente, para el año 2017 el IHH se ubicó en 1263 puntos, ratificando que, de los 25 bancos existentes para este año, 10 concentraban el $90 \%$ del total de los activos.

El cálculo del IHH permite identificar cómo la industria bancaria del país ha tenido una conducta positiva hacia la concentración del mercado, evidenciando un bajo nivel en la primera parte de la década del 2000, presentando una estructura de mercado tendiente a la competencia, la cual ha venido aumentando paulatinamente. En la actualidad el sector está cada vez más concentrado presentando una estructura oligopólica, donde 4 grupos bancarios se consolidan acaparando el $74 \%$ de los activos totales del sector bancario.

En la actualidad se evidencia en el sector bancario colombiano la existencia de 4 grupos que acaparan el $74 \%$ del total de los activos del sistema, siendo el caso del Grupo AVAL, Bancolombia y Davivienda de origen nacional, quienes representan el $26 \%, 25 \%$ y $13 \%$, y BBVA de origen extranjero con una participación del 10\% en el total de activos. El otro $26 \%$ de la participación de los activos totales corresponde a 17 entidades restantes existentes a diciembre del año 2017, evidenciando de esta forma el gran poder de mercado que poseen estos grupos en las diversas actividades desempeñadas en el sector bancario.

Lo anterior se manifiesta en el buen desempeño financiero y de mercado de los 4 grupos mencionados, reflejado mediante las buenas prácticas en la administración de sus recursos, la incursión en nuevos mercados (Centroamérica y el Caribe), la introducción de servicios digitales que facilitan el acceso a los usuarios y la expansión en el mercado interno por medio de corresponsales bancarios a lugares donde la banca colombiana no tenía presencia ni representación alguna.

\section{El modelo econométrico}

La hipótesis de la incidencia positiva de la concentración bancaria en el margen de intermediación tiene sus antecedentes. Es el caso del trabajo de Mody y Peria (2004), donde se analiza el impacto de la participación de los bancos extranjeros y la concentración bancaria en el margen de intermediación para Colombia, Argentina, Chile, México y Perú. Teniendo como medida de concentración el IHH, y siendo esta una de las variables independientes en el modelo, se confirmó como la concentración bancaria tiene un impacto positivo en los diferenciales bancarios (Mody \& Peria, 2004). Asimismo, se evidencia con otros índices de concentración 
el mismo efecto, por ejemplo en el modelo, al incluir todos los bancos (domésticos y extranjeros) se observa que ante variaciones de 0,13 en la concentración bancaria los diferenciales bancarios reaccionan de la misma forma incrementándose en 0,25. En el modelo se incluyen otras variables independientes (liquidez, patrimonio bancario, participación de bancos extranjeros, etc.) que también afectan el margen de intermediación, lo que indica que no sólo la concentración explica en su totalidad los cambios en los márgenes de intermediación bancaria (Mody \& Peria, 2004).

También, Jopen (2013) muestra la incidencia positiva del poder de mercado en los márgenes de intermediación financiera en la banca peruana a partir del año 2003, cuando la reducción del número de entidades existentes en el país y el aumento en los niveles de concentración de la industria bancaria provocaron un crecimiento en el margen de intermediación.
Utilizando datos panel para Colombia. Flórez y Saldarriaga (2011) estiman que la concentración bancaria incide positivamente en el margen de intermediación, lo cual a incrementa los márgenes de captación y colocación.

Por ende, en la estructura de mercado oligopólica los margenes de intervención no son tan elevados como en la existencia de monopolio, pero, no tan bajas como en competencia perfecta, lo cual ocurre por el poder de mercado que se tiene en cada estructura de mercado, manifestándose con la siguiente hipótesis: a medida que haya mayor poder de mercado también habrá mayor margen de intermediación, por lo que si existe un mayor poder de mercado en el sector, las entidades pueden fijar tasas de interés de colocación más elevadas y ofrecer al público menores tasas de captación. En la Figura 3 se observa la relación positiva entre el nivel de concentración bancaria y el margen de intermediación bancaria en Colombia.

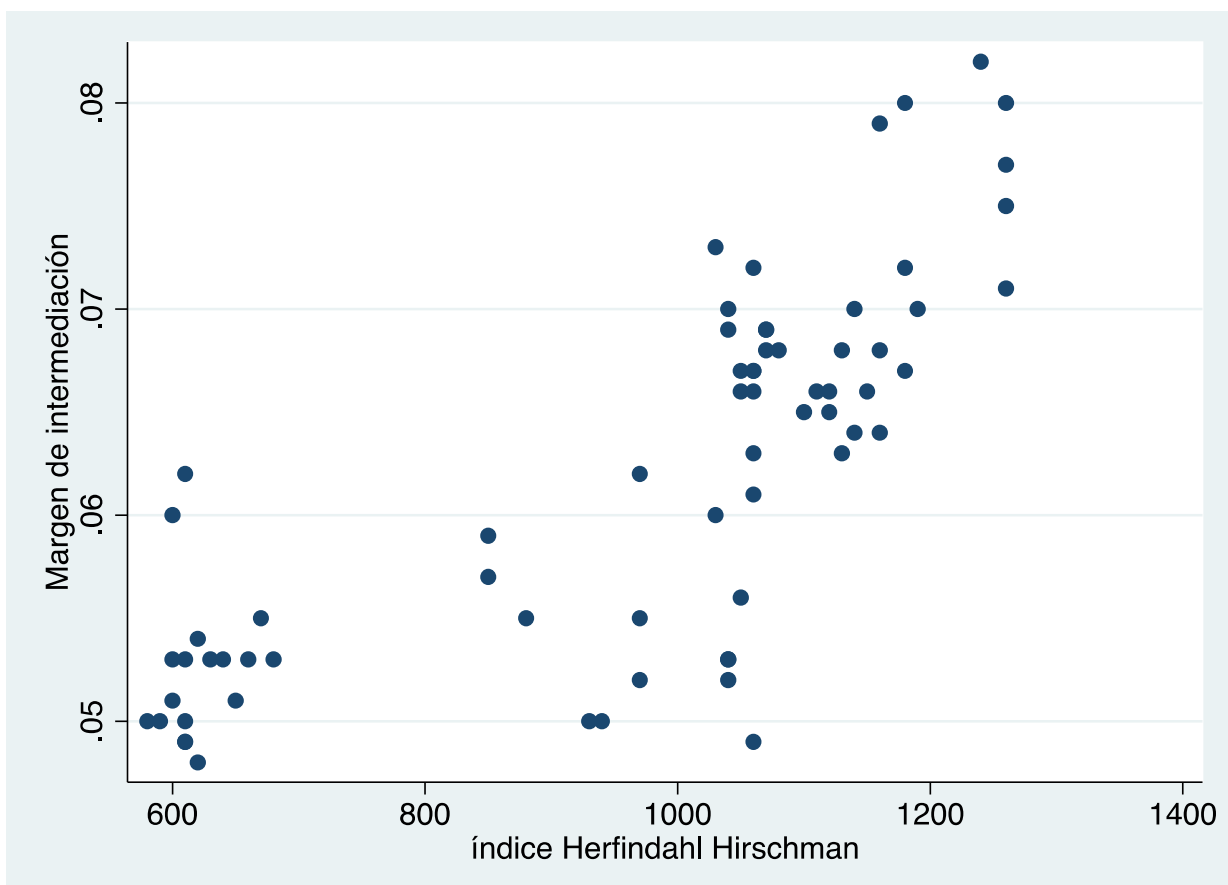

Figura 3. Correlación entre el margen de intermediación y el IHH.

Fuente: Datos tomados del Banco de la República 
Se formula un modelo autorregresivo con rezagos distribuidos (ARDL), el cual identifica la relación de cointegración (largo plazo) entre las variables indepedientes y el Margen de Intermediación ( $m i$ ). En este modelo se considera como la variable endógena (margen de intermediación) en función de diferentes variables en el tiempo, por lo que existe una forma estructural. La concentración bancaria se mide con el Índice Herfindahl-Hirschman para el sector (ihh), y para facilitar el análisis se divide en 10.000. En el modelo se asume que una mayor concentración otorga mayor poder de mercado, y así mayor diferencial de tasas.

Las otras variables independientes son factores macroeconómicos que inciden en la determinación del diferencial entre las tasas de colocación y captación, tales como: el crecimiento del PIB real, la inflación y el encaje legal. Estos factores son definidos en el trabajo de Almeida y Divino (2015). Por el lado de la variación del PIB real (var_pib) se identifica el papel de la actividad económica en los costos financieros en el país, donde un valor significativo muestra que el crecimiento económico modifica los patrones de fijación de tasas de interés de los bancos. La incidencia de la inflación (inf) depende de la indexación de las tasas de interés (Perry, 1992), donde un efecto positivo implica que los bancos no pierden poder adquisito de sus créditos, pero no compensan de la misma manera a los depositantes. Finalmente, el mayor encaje bancario (enc) implica una mayor represión financiera, porque los bancos dejan de prestar este monto al público, y ocasiona que los bancos eleven las tasas de interés de los créditos por encima de lo que pagan en la captación (Fama, 1985).

El modelo ARDL incluye variable estacionarias (media y varianza constante) y no estacionarias, para encontrar una relación de largo plazo entre el margen de intermediación y las variables explicativas (2).

En la ecuación (2) el margen de intermediación del sector bancario (mi) está determinado por su dinámica propia, es decir, está definido por un proceso autorregresivo de orden $p$ (es el número de rezagos de la variable dependiente). Las demás variables explican el comportamiento de $M I$ en el tiempo en un orden q (es el número de rezagos de las variables explicativas). Por lo tanto, el modelo ARDL $\left(p, q_{1}, q_{2}, q_{3}, q_{4}\right)$ se determina en un proceso de selección de rezagos definido con un criterio de información, lo cual permite estimar el modelo de corrección de errores y los efectos de corto y largo plazo, y para esto se transforma la ecuación (2) en (3).

$$
\begin{aligned}
m i_{t}=\alpha & +\sum_{j=1}^{n} \rho_{j} m i_{t-j}+\sum_{j=0}^{p} \beta_{1 j} i h h_{t-j}+\sum_{j=0}^{q} \beta_{2 j} i n f_{t-j} \\
& +\sum_{j=0}^{q} \beta_{3 j} v a r_{-} p i b_{t-j}+\sum_{j=0}^{q} \beta_{4 j} e n c_{t-j}+\mu_{t}
\end{aligned}
$$


El valor del coeficiente $\delta$ captura la respuesta del margen de intermediación a la desviación de la relación de equilibrio en un periodo, o también la corrección de la distorsión de la relación de cointegración. Los valores de $\theta$ son los coeficientes de largo plazo, y reflejan la incidencia en el tiempo de las variables independientes, que se miden como $\theta_{\mathrm{k}}=\sum_{\mathrm{j}=0}^{\mathrm{p}} \beta_{\mathrm{kj}} / \delta$. Los valores de $\tau$ son los coeficientes de corto plazo. En síntesis, las ecuaciones (2) y (3) se deben estimar para obtener los efectos de largo plazo de los factores macroeconómicos sobre el margen de intermediación bancario.

Los datos a utilizar tienen frecuencia trimestral entre el año 2000 y el año 2017. La medición de las variables se define:

Margen de intermediación: es el resultado de la diferencia entre la tasa de colocación y la tasa de captación obtenida del promedio trimestral, calculada con base en las estadísticas reportadas por BanRepública.
Índice Herfindahl- Hirschman: La serie de datos construida con base a los activos de cada banco (Figura 2). En la estimación del modelo se toma el índice dividido en 10.000, quedando el máximo nivel de concentración en 1.

Encaje bancario: corresponde a la serie de datos obtenida del Banco de la República, tomando el tipo de encaje ordinario. Esta variable puede tener efectos positivos en el margen de intermediación.

Variación trimestral del PIB: una vez obtenida la información del PIB trimestral de la base de datos del Banco de la República, basados en la metodología del año 2005, se calculó la variación porcentual y se organizaron los datos obtenidos.

Tasa de inflación: la serie de datos se obtiene del Banco de la República en periodicidad mensual y se promedia para obtener el resultado trimestral.
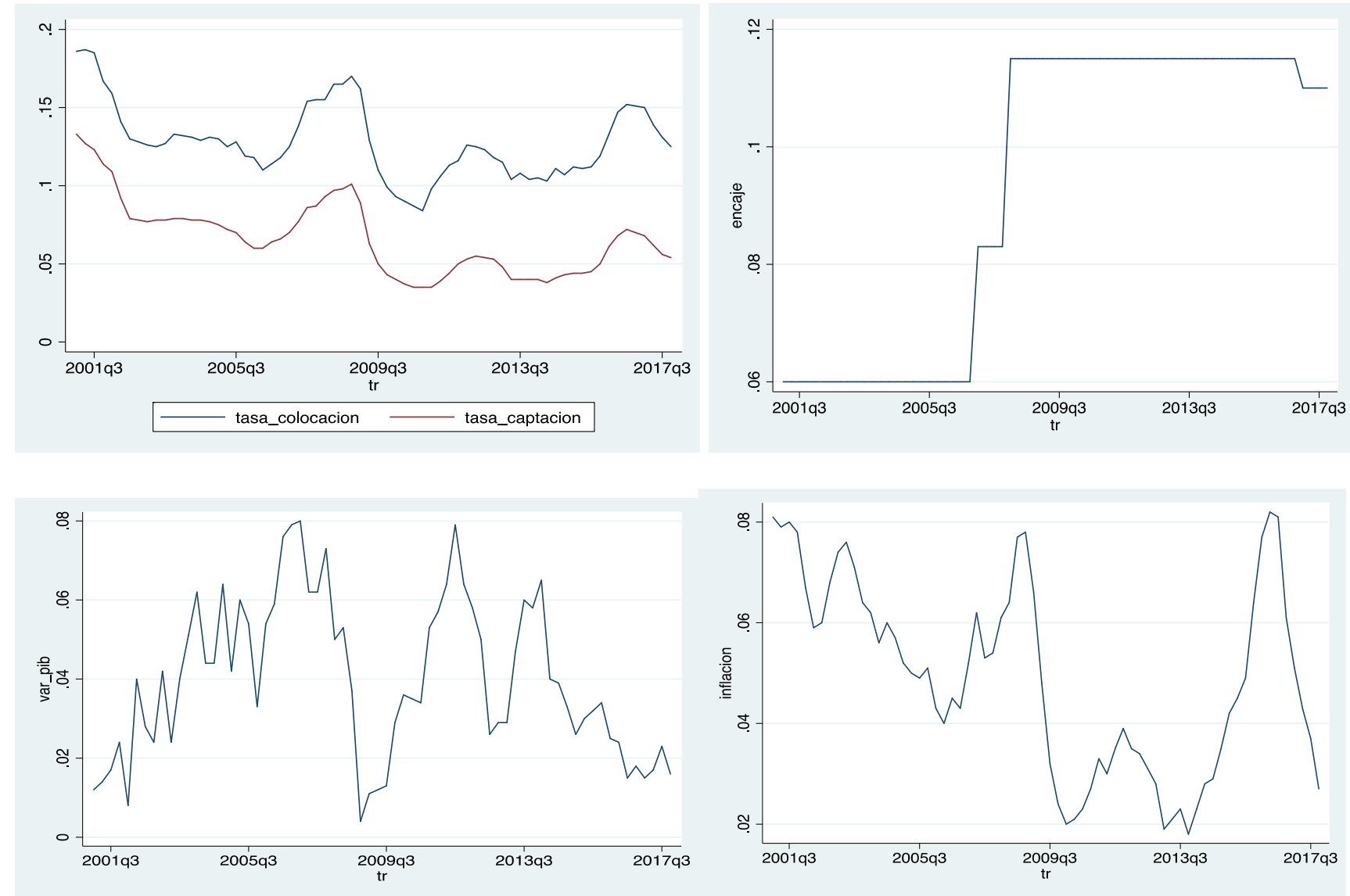

Figura 4. Comportamiento de variables.

Fuente: Datos tomados del Banco de la República. 


\section{Resultados}

El análisis requiere identificar el orden de integración de las variables, con el propósito de precisar si las series son estacionarios en niveles, por lo que se aplica la prueba de Dickey-Fuller. En la Tabla 1 se evidencia la prueba de raíz unitaria, donde la hipótesis nula es que la serie tiene raíz unitaria, y por ende no es estacionaria. Se encuentra que las series, excepto var_pib, tienen raíz unitaria en niveles, es decir, son integradas de orden uno (I(1)), y var_pib es $\mathrm{I}(0)$.
TABLA 1.

Prueba de raíz unitaria para las variables.

\begin{tabular}{cccc}
\hline Variable & Estadístico z & Valor p & $\begin{array}{c}\text { Orden de } \\
\text { integración }\end{array}$ \\
\hline mi & -1.858 & 0.3521 & $\mathrm{I}(1)$ \\
ihh & -0.935 & 0.7763 & $\mathrm{I}(1)$ \\
var_pib & -2.874 & 0.0484 & $\mathrm{I}(0)$ \\
Inflación & -1.782 & 0.3895 & $\mathrm{I}(1)$ \\
Encaje & -1.174 & 0.6848 & $\mathrm{I}(1)$ \\
\hline
\end{tabular}

Fuente. Elaboración propia.

TABLA 2.

Regresión de la ecuación (1)

Muestra: 2002q1 - 2017q4

Número de observaciones $=64$

$\mathrm{F}(15,48)=40.12$

$\mathrm{R}$ cuadrado $=0.9261$

$\mathrm{R}$ cuadrado ajustado $=0.9030$

\begin{tabular}{|c|c|c|c|c|}
\hline margen de intermediación & Coeficiente & Error estándar & Estad t & Valor $\mathrm{P}$ \\
\hline margen de intermediación $(-1)$ & 0.453767 & 0.1280933 & 3.54 & 0.001 \\
\hline margen de intermediación (-2) & 0.1803404 & 0.1335211 & 1.35 & 0.183 \\
\hline margen de intermediación (-3) & -0.2357393 & 0.1352549 & -1.74 & 0.088 \\
\hline margen de intermediación $(-4)$ & 0.2394089 & 0.1130575 & 2.12 & 0.039 \\
\hline ihh & 0.1264246 & 0.0485952 & 2.6 & 0.012 \\
\hline inflación & 0.0189001 & 0.0618642 & 0.31 & 0.761 \\
\hline inflación (-1) & 0.2086119 & 0.0750589 & 2.78 & 0.008 \\
\hline var_pib & 0.061006 & 0.0368487 & 1.66 & 0.104 \\
\hline var_pib (-1) & 0.0639281 & 0.0403876 & 1.58 & 0.12 \\
\hline var_pib (-2) & 0.0664969 & 0.0339918 & 1.96 & 0.056 \\
\hline encaje & -0.276728 & 0.0853199 & -3.24 & 0.002 \\
\hline encaje $(-1)$ & 0.2621003 & 0.1084193 & 2.42 & 0.019 \\
\hline encaje (-2) & -0.0438476 & 0.1117488 & -0.39 & 0.697 \\
\hline encaje (-3) & -0.0064633 & 0.1110936 & -0.06 & 0.954 \\
\hline encaje (-4) & 0.1755385 & 0.0864192 & 2.03 & 0.048 \\
\hline Constante & -0.0183457 & 0.0067421 & -2.72 & 0.009 \\
\hline
\end{tabular}

Fuente. Elaboración propia. 
La selección de rezagos se hace mediante el criterio de información de Akaike, lo que lleva a formar un ARDL $(4,0,1,2,4)$. El orden del modelo significa que la dinámica del diferencial bancario depende hasta de cuatro rezagos, es decir, del comportamiento anual; el orden cero del efecto del IHH en el diferencial de tasas implica que la incidencia de la concentración bancaria se obtiene en forma contemporánea, por lo que en el mismo trimestre se refleja los cambios en la estructura de la industria. Por su parte, la inflación del trimestre anterior incide en el margen de tasas del trimestre actual, la actividad económica determina dicho margen desde dos trimestres atrás, y el cambio en el encaje legal traspasa su efecto durante cuatro trimestres.

En la Tabla 2 se observa como en el proceso autorregresivo (AR) de orden 4 no determina que todos los coeficientes asociados sean estadísticamente significativos, porque el AR(1) es significativo al 1\%, el AR(3) lo es al $10 \%$ y el AR(4) es al $5 \%$. También se evidencia cierta corrección en el proceso de dependencia histórica del margen de tasas de interés. En el caso de la incidencia de la concentración bancaria se evidencia una respuesta contemporánea del margen de tasas, lo que implica el aumento de la brecha entre la tasa de colocación y captación en el mismo trimestre que la concentración de la industria cambia.

Por el lado de la inflación, se observa un efecto estadísticamente significativo de un trimestre al siguiente, por lo que este es el tiempo que tarda el ajuste de los bancos a la variación en el poder adquisitivo del crédito. En el caso de la variación del PIB, se evidencia una incidencia estadísticamente significativa después de dos trimestres, por lo que se deduce una tardía modificación de las tasas de interés a los cambios en la actividad económica. Finalmente, la respuesta del diferencial de tasas a la modificación del requerimiento de encaje se hace en el mismo trimestre de la medida de política, y es persistente en el tiempo.

La existencia de una relación de largo plazo entre las variables se identifica a través de la prueba de límite, donde se considera como hipótesis nula la existencia de relación de cointegración entre las variables. En la Tabla 3, se observa que a nivel global existe relación de cointegración y a nivel individual sólo la variable I(0). En ese sentido, se concluye que es posible obtener los efectos de largo plazo de los factores macroeconómicos sobre el margen de tasas de interés, y se estima el modelo de corrección de errores.

TABLA 3.

Prueba de límite

\begin{tabular}{|c|c|c|c|c|c|c|c|c|}
\hline \multicolumn{9}{|c|}{ Pesaran, Shin, and Smith (2001) bounds test } \\
\hline \multicolumn{9}{|c|}{ H0: no level relationship $\mathrm{F}=8.267$} \\
\hline \multicolumn{9}{|c|}{ Finite sample (4 variables, 64 observations, 10 short-run coefficients) } \\
\hline \multicolumn{9}{|c|}{ Kripfganz and Schneider (2018) critical values and approximate p-values } \\
\hline & \multicolumn{2}{|c|}{$10 \%$} & \multicolumn{2}{|c|}{$5 \%$} & \multicolumn{2}{|c|}{$1 \%$} & \multicolumn{2}{|c|}{ p-value } \\
\hline & $\mathrm{I}(0)$ & $\mathrm{I}(1)$ & $\mathrm{I}(0)$ & $\mathrm{I}(1)$ & $\mathrm{I}(0)$ & $\mathrm{I}(1)$ & $\mathrm{I}(0)$ & $\mathrm{I}(1)$ \\
\hline $\mathrm{F}$ & 2.488 & 3.735 & 2.976 & 4.365 & 4.092 & 5.784 & 0.00 & 0.001 \\
\hline $\mathrm{t}$ & -2.494 & -3.587 & -2.831 & -3.972 & -3.501 & -4.724 & 0.018 & 0.162 \\
\hline
\end{tabular}

Fuente: Elaboración propia. 
TABLA 4.

Regresión de la ecuación (2)

\begin{tabular}{|c|c|c|c|c|}
\hline \multicolumn{5}{|l|}{ Muestra: 2002q1 - 2017q4 } \\
\hline \multicolumn{5}{|l|}{ Número de observaciones $=64$} \\
\hline \multicolumn{5}{|l|}{$\mathrm{R}$ cuadrado $=0.5954$} \\
\hline \multicolumn{5}{|l|}{$\mathrm{R}$ cuadrado ajustado $=0.4690$} \\
\hline D.margen de intermediación & Coeficiente & Error estándar & Estad t & Valor P \\
\hline \multicolumn{5}{|l|}{ Ajuste } \\
\hline margen de intermediación (-1) & -0.362223 & 0.1104583 & -3.28 & 0.002 \\
\hline \multicolumn{5}{|l|}{ Largo plazo } \\
\hline ihh & 0.3490242 & 0.1019675 & 3.42 & 0.001 \\
\hline inflación & 0.6280993 & 0.2100424 & 2.99 & 0.004 \\
\hline var_pib & 0.5284891 & 0.2269018 & 2.33 & 0.024 \\
\hline encaje & 0.3053367 & 0.1281935 & 2.38 & 0.021 \\
\hline \multicolumn{5}{|l|}{ Corto plazo } \\
\hline D.margen de intermediación (-1) & -0.18401 & 0.1288424 & -1.43 & 0.16 \\
\hline D.margen de intermediación (-2) & -0.0036696 & 0.1287406 & -0.03 & 0.977 \\
\hline D.margen de intermediación (-3) & -0.2394089 & 0.1130575 & -2.12 & 0.039 \\
\hline D.inflación & -0.2086119 & 0.0750589 & -2.78 & 0.008 \\
\hline D.var_pib & -0.130425 & 0.0436515 & -2.99 & 0.004 \\
\hline D. var_pib (-1) & -0.0664969 & 0.0339918 & -1.96 & 0.056 \\
\hline D.encaje & -0.3873279 & 0.0878329 & -4.41 & 0.000 \\
\hline D.encaje (-1) & -0.1252276 & 0.0975644 & -1.28 & 0.205 \\
\hline D.encaje (-2) & -0.1690752 & 0.0903309 & -1.87 & 0.067 \\
\hline D.encaje (-3) & -0.1755385 & 0.0864192 & -2.03 & 0.048 \\
\hline Constante & -0.0183457 & 0.0067421 & -2.72 & 0.009 \\
\hline
\end{tabular}

Fuente: Elaboración propia.

La estimación del modelo que explica la incidencia de la concentración bancaria y de otros determinantes macroeconómicos sobre el margen de tasas de interés se muestra en la tabla 4. Se estiman tres aspectos: la corrección de los desequilibrios de corto plazo de la relación de equilibrio de largo plazo, los efectos de largo plazo, y los efectos de corto plazo. En el caso del ajuste a los desequilibrios de corto plazo se observa un valor negativo y una significancia estadística, lo cual apoya la relación de cointegración.
En los efectos de largo plazo se evidencian en todas las variables seleccionadas. La concentración bancaria tiene una incidencia positiva en el largo plazo. Por tanto, un aumento en 1\% (100 puntos en el valor del índice original) origina que en promedio en el largo plazo el margen de tasas de interés sea $0.35 \%$ más alto. Esto implica que un incremento en la concentración bancaria ocasiona que las tasas de interés de los créditos se eleven y las tasas de captación desciendan o se mantengan, debido al poder de mercado que permite a los bancos tener 
mayor control sobre los precios (tasas de interés). El resultado obtenido es consistente con lo esperado, puesto que en el periodo 2000-2017 el sector bancario colombiano tuvo incrementos importantes en los márgenes de intermediación y un aumento en los niveles de concentración, siendo el principal resultado de acuerdo con el objetivo del documento.

Por su parte, la inflación incide positivamente a largo plazo en el margen de intermediación, siendo que 1\% más de inflación ocasiona una mayor diferencia en promedio entre las tasas de colocación y de captación de $0.63 \%$. Esto implica que los bancos indexan las tasas de los créditos a la inflación, por lo que cuando se eleva la inflación las tasas de colocación suben y las tasas de captación lo hacen en menor medida, y cuando la inflación desciende las tasas de colocación bajan poco y las tasas de captación si lo hacen al mismo ritmo que la variación de los precios.

La variación del PIB tiene una incidencia positiva, donde $1 \%$ más de crecimiento económico eleva el margen de tasas en promedio $0.53 \%$, debido a que la expansión en la actividad económica implica una expansión del sector bancario (mayor tamaño de los bancos con más poder de mercado). Finalmente, la tasa de encaje también un incidencia positiva a largo plazo, porque mayor represión financiera implicará mayores costos de los créditos.

Las relaciones mencionadas en el modelo coinciden con la teoría económica, ya que el poder de mercado que posea cada entidad se verá reflejado en los niveles de ganancias de las mismas, propiciados en buena parte por ingresos de intermediación, los cuales también se ven afectados levemente por los niveles de inflación de la economía, que a su vez sirven como guía para elevar o disminuir las tasas de colocación y captación.

En el corto plazo los resultados son contrarios, porque se obtienen valores negativos en los coeficientes. Esto se debe a que de un trimestre a otro los margenes de tasas se van ajustando, pero la incidencia importante en una relación de cointegración es a largo plazo. En los anexos se muestran las diferentes pruebas de diagnóstico del modelo estimado, y se deduce que el modelo no tiene autocorrelación de residuos y su errores son normales e insesgados.

\section{Conclusiones}

La evidencia empírica acerca del papel del sector bancario en Colombia se ha venido consolidando gracias a distintos aportes, que desde diversos puntos de vista exponen cómo ha evolucionado la economía y el sector en general, debido a ello, y teniendo en cuenta la crisis del sector que surgió a finales de la década de los años 90 's, se evidencian modificaciones en la estructura del sistema, generando cambios en las dinámicas de concentración y competencia.

El sector bancario colombiano es uno de los más vigilados y regulados de la economía nacional, y por ello también es uno de los más eficientes y productivos. La estricta regulación de la Superfinanciera ha permitido que se presenten indicadores positivos en los niveles de liquidez y solvencia, llevando a que las entidades puedan cumplir con sus obligaciones tanto a corto como a largo plazo. La apuesta por el aumento de la bancarización y la expansión de algunas entidades a distintas partes del territorio nacional se debe a nuevas sucursales, la presencia de corresponsales bancarios y la 
inclusión de servicios financieros a través de la tecnología.

La crisis experimentada por el sector a finales de los 90 permitió que se aceleraran los procesos de fusiones, adquisiciones, conversiones, bancos liquidados y la entrada de nuevas entidades al país, ocasionando una reducción en el número de entidades existentes, y permitiendo que se consolidaran cuatro grupos bancarios, los cuales tienen el control del $75 \%$ de los activos totales de las entidades del sistema bancario. En el periodo comprendido entre los años 2000-2007 se llevaron a cabo los principales procesos de fusiones y adquisiciones en el sector, mientras que en años posteriores (2008-2012) se dio un proceso de conversión de entidades comerciales financieras a bancos, finalmente, se ha presentado la entrada de capital extranjero al sector y de algunas entidades dedicadas al microcrédito.

En términos generales, la concentración del sector ha venido aumentando considerablemente, en el año 2000 el IHH se ubicó en 648 puntos y a finales del año 2017 en 1263 puntos, permitiendo establecer que el sector está acercándose a un mayor nivel de concentración similar a la estructura oligopólica. A la vez, existe una relación entre la tasa de inflación y los márgenes de intermediación del sector bancario colombiano, que permiten establecer que ante variaciones en los niveles de concentración y de inflación habrá cambios en los márgenes de intermediación, de este modo el poder de mercado es uno de los factores que mayor incidencia tiene al momento de fijar el diferencial entre las tasas de captación y colocación. También existe incidencia positiva en los margenes de tasas de interés la variación del PIB real y el encaje, lo que explica el papel de la actividad económica y de la represión en los costos de intermediación bancaria.

\section{REFERENCIAS}

Almeida, F. D. \& Divino, J. A. (2015). Determinants of the banking spread in the Brazilian economy: The role of micro and macroeconomic factors. International Review of Economics \& Finance, 40, 29-39.

ANIF. (2006). Fusiones y Adquisiciones en el Sector Financiero Colombiano. Bogotá, D.C.: Anif.

Bernal, R. (2007). Concentración y Competencia en el Sistema Financiero Crediticio Colombiano en la última década. Borradores de Economía, 432. [Online]. Recuperado de https://www. banrep.gov.co/es/concentracion-y-competencia-el-sistema-financiero-crediticio-colombiano-ultima-decada

Bonilla, E., Cardeño, N. \& Cardeño, E. (2015). La función financiera en las micros, pequeñas y medianas empresas, del municipio de Riohacha. Económicas CUC, 36(2), 137-146. Recuperado a partir de https://revistascientificas.cuc. edu.co/economicascuc/article/view/762

Cárdona, A. \& Restrepo, J. D. (2012). Fusiones y adquisiciones, concentración y poder de mercado en el sector bancario colombiano 2000-2011. [Tesis Magister]. Medellín: EAFIT.

Clavijo, S. (2000). Hacia la Multibanca en Colombia: retos y "retazos". Borradores de Economía. [Online]. Recuperado de http://banrep.gov.co/docum/ftp/borra150.pdf

Dinero. (abril 11, 2018). ¿Cómo funcionan los neobancos? [Online]. Disponible en https://www.dinero.com/: https://www. dinero.com/empresas/articulo/que-sonlos-neobancos/257166

Dinero. (marzo 28, 2008). Bancos, dura competencia. [Online]. Disponible en https://www.dinero.com/edicion-impresa/negocios/articulo/bancos-dura-competencia/59915 
Estrada, D. (2005). Efectos de las Fusiones sobre el Mercado Financiero Colombiano. Borradores de Economía, 329. [Online]. Recuperado de https://www. banrep.gov.co/sites/default/files/publicaciones/pdfs/borra329.pdf

Fama, E. F. (1985). What's different about banks? Journal of monetary economics, 15(1), 29-39.

Flórez, J. \& Saldarriaga, J. (2011). Concentración bancaria, margen de intermediación en Colombia: 1995-2011. Gestión y Región 12, 7-28.

González, R., Galeano, H. \& Trejos, L. (2015). Estados Unidos en la política exterior colombiana: ¿aliado incondicional?, Económicas CUC, 36(1), 79106. http://dx.doi.org/10.17981/econcuc.36.1.2015.23

Guerrero, R. \& Noriega, H. (2015). Impuesto predial: Factores que afectan su recaudo. Económicas CUC, 36(1), 71-80. Recuperado a partir de https://revistascientificas.cuc.edu.co/economicascuc/article/view/674

Janna, M. (2003). Eficiencia en costos, cambios en las condiciones generales de mercado y crisis en la banca colombiana:1992-2002. Borradores de Economía. [Online]. Recuperado de http:// www.banrep.gov.co/sites/default/files/ publicaciones/pdfs/borra260.pdf

Jiménez, A. \& Jaramillo, A. (2001). Empresa y Coyuntura económica: análisis de entidades bancarias. [Documentos de Trabajo CIEF 003923]. Medellín: Universidad EAFIT. Recuperado de https:// ideas.repec.org/p/col/000122/003923. html

Jopen, G. (2013). Poder de mercado, intermediación financiera y banca: un enfoque de organización industrial. Revista Economía PUCP, 32.

Mody, A. \& Peria, M. S. M. (2004). How foreign participation and market concentration impact bank spreads: evi- dence from Latin America [WPS3210]. Washington: World Bank Publications. Montoya, G., Martínez, C., Lacouture, D. \& Castillo, L. (2015). Informe Asobancaria. Bogotá, D.C.: Asobancaria.

Mora, A., Serna, M., \& Serna, N. (2011). Las entidades bancarias en Colombia, consecuencia de un movimiento constante del sector bancario. $M B A, 22$. 32-53.

Morales, M. A. (2011). Concentracion y estabilidad financiera: el caso del sistema bancario colombiano. Temas de Estabilidad Financiera-Banco de la República, 58. [Online]. Recuperado de http://www.banrep.gov.co/es/estabilidad-tema-58

OCDE. (2017). Estudios Económicos de la OCDE Colombia. Bogotá, D.C.: OECD Economic Surveys.

Pérez, M. E., Hernández, J., Acosta, I. \& Chumaceiro, A. (2009). Consideraciones teóricas para el análisis de las Pequeñas y Medianas Empresas como fuente de generación de empleo y su correspondencia ética con la Sociedad. Revista Formación Gerencial, 8(2), 272-297

Perry, P. (1992). Do banks gain or lose from inflation? Journal of Retail Banking, 14(2), 25-31.

Ramirez, Y. \& Romero, M. (2014). Informe de Sostenibilidad-Acercando la banca a los colombianos. Bogotá, D.C.: Babel Group S.A.S.

Ramírez, Y., Gamboa, J., \& Mesa, A. (2015). Informe de Sostenibilidad-Acercando la banca a los colombianos. Bogotá, D.C.: Poder \& Poder.

República de Colombia. Congreso de la República. (21 de octubre de 2014). Por la cual se dictan medidas tendientes a promover el acceso a los servicios inancieros transaccionales y se dictan otras disposiciones. [Ley 1735]. Diario Oficial: 49.311. 
República de Colombia. Congreso de la República. (3 de agosto de 1999). Por la cual se dictan disposiciones en relación con el sistema financiero y asegurador, el mercado público de valores, las Superintendencias Bancaria y de Valores y se conceden unas facultades. [Ley 510]. DO: 43.654.

República de Colombia. Congreso de la República. (23 de diciembre de 1999). Por la cual se dictan normas en materia de vivienda, se señalan los objetivos y criterios generales a los cuales debe sujetarse el Gobierno Nacional para regular un sistema especializado para su financiación, se crean instrumentos de ahorro destinado a dicha financiación, se dictan medidas relacionadas con los impuestos y otros costos vinculados a la construcción y negociación de vivienda y se expiden otras disposiciones. [Ley 546]. DO: 43.827.

Steiner, R., Barajas, A. \& Salazar, N. (1997). El Margén de Intermediación Bancaria 1991-1996. Repositorio Fedesarrollo. [Online]. Recuperado de http://hdl.handle.net/11445/3269

Suescún, R. \& Misas, M. (1996). Cambio Tecnológico,ineficiencia de escala e ineficiencia X en la Banca Colombiana. Borradores de Economía. [Online]. Recuperado de https://www.banrep. gov.co/es/cambio-tecnologico-ineficiencia-escala-e-ineficiencia-x-banca-colombiana

Upegui, A. M. (2014). Fusiones y adquisiciones en el sector bancario colombiano . Repositorio institucional universidad EAFIT, 34.

Zuñiga, J. (2017). De la función económica del cheque, del cheque común al de pago diferido. Jurídicas CUC, 13(1), 183-198. https://doi.org/10.17981/juridcuc.13.1.2017.08

\section{ANEXOS}

\section{PRUEBAS DE DIAGNÓSTICO}

TABLA 5

Prueba de autocorrelación serial

\begin{tabular}{cccc}
\hline \multicolumn{4}{c}{ Breusch-Godfrey LM test for autocorrelation } \\
\hline $\operatorname{lags}(\mathrm{p})$ & $\mathrm{F}$ & $\mathrm{df}$ & Prob $>\mathrm{F}$ \\
1 & 0.034 & $(1,47)$ & 0.8538 \\
2 & 0.035 & $(2,46)$ & 0.9652 \\
3 & 0.681 & $(3,45)$ & 0.568 \\
4 & 0.825 & $(4,44)$ & 0.5166 \\
\hline
\end{tabular}

Fuente: cálculos propios.

TABLA 6

Pruebas de normalidad

\begin{tabular}{|c|c|c|c|c|c|}
\hline \multicolumn{6}{|c|}{ Skewness/Kurtosis tests for Normality } \\
\hline Variable & Obs & $\begin{array}{c}\operatorname{Pr} \\
\text { (Skewness) }\end{array}$ & $\begin{array}{c}\operatorname{Pr} \\
\text { (Kurtosis) }\end{array}$ & $\begin{array}{c}\text { adj } \\
\operatorname{chi} 2(2)\end{array}$ & $\begin{array}{c}\text { Prob } \\
>\text { chi2 }\end{array}$ \\
\hline Residual & 64 & 0.1994 & 0.2042 & 3.41 & 0.1819 \\
\hline
\end{tabular}

Fuente: Elaboración propia.

\footnotetext{
${ }^{1}$ Para el cálculo de las tasas activas y pasivas los informes de estabilidad financiera del Banco de la República utilizan la metodología A2, aplicada por Janna en el documento: "Medición y evolución de los márgenes de intermediación financiera para el caso colombiano 1996-2001", donde la tasa activa se calcula como la proporción entre los ingresos recibidos por cartera y la cartera bruta total y las tasas pasivas como la razón de todos los intereses pagados sobre los depósitos, fondos interbancarios comprados y pactos de recompra, créditos de bancos y títulos de inversión en circulación.

${ }^{2}$ CAV's: hace referencia a las corporaciones de ahorro y vivienda, las cuales tenían como finalidad promover el ahorro privado y canalizarlo hacia la industria de la construcción

${ }^{3}$ El Joint venture es un tipo de contrato entre dos o más empresas para la consecución de un mismo objetivo, se desarrolla cuando un proyecto concreto requiere una elevada inversión para realizar la actividad por separado y cada una de las empresas sigue desarrollando la actividad principal (Tomado del sitio WEB: Debitoor Glosario definición).
} 


\section{Biodata}

José Mauricio Gil León es Profesor de la Universidad Pedagógica y Tecnológica de Colombia. Economista y Especialista en Finanzas y Magister en Economía. https:// orcid.org/0000-0002-5653-5245

\section{Dilsa Eliyer Castellanos Castellanos} es Economista de la Universidad Pedagógica y Tecnológica de Colombia. https://orcid. org/0000-0002-5649-288X

Diego Leonardo González Rodriguez es Economista de la Universidad Pedagógica y Tecnológica de Colombia. https://orcid. org/0000-0003-4331-3472 